\title{
Hepatic cerebrospinal fluid pseudocyst mimicking hydatid liver disease: a case report
}

\author{
Walid Faraj, , Houssein Haidar Ahmad, Deborah Mukherji and Mohamed Khalife
}

\begin{abstract}
Introduction: An abdominal pseudocyst is a rare complication of a ventriculo-peritoneal shunt. Etiological factors include infection, obstruction and dislodgement. This is the first report of a hepatic cerebrospinal fluid pseudocyst mimicking hydatid liver disease.

Case presentation: We report the case of an 18-year-old Caucasian male patient who presented with a hepatic pseudocyst secondary to a ventriculo-peritoneal shunt, misdiagnosed as hydatid disease of the liver.

Conclusion: Hepatic pseudocysts, a rare complication of a ventriculo-peritoneal shunt, have similar clinical and radiological characteristics to those of hydatid liver disease. The formation of a pseudocyst should always be considered in patients with ventriculo-peritoneal shunts in situ.
\end{abstract}

\section{Introduction}

An abdominal pseudocyst is a rare complication of a ventriculo-peritoneal shunt. Such cysts may cause diagnostic problems in regions such as the Middle East, where echinococcosis disease of the liver is endemic, due to similarities in clinical presentation and radiological appearance.

\section{Case presentation}

An 18-year-old Caucasian male patient presented with a 10-day history of generalized tonic-clonic seizures. His past medical history included right ventriculo-peritoneal (VP) shunt insertion at two weeks of age for bacterial meningitis complicated by hydrocephalus. Four years prior to his current admission he had presented with abdominal pain and a computed tomography (CT) scan of his abdomen at that time was interpreted as being consistent with a right hepatic hydatid cyst $(8 \times 6 \mathrm{~cm})$. Serology workup was negative for hydatid disease at the time of the CT scan, however, due to the characteristic radiological findings, antihelminthic treatment (albendazole) was commenced and he was subsequently lost to follow-up.

During his current admission, he underwent a CT scan of his brain and abdomen, which revealed an

\footnotetext{
* Correspondence: wf07@aub.edu.lb

HBP and Liver Transplant Unit, Department of Surgery, American University of Beirut-Medical Centre, American University of Beirut Street, Beirut-Lebanon
}

increase in the size of the cerebral ventricles and an increase in the size of the liver cyst $(11 \times 9 \mathrm{~cm})$, revealing the presence of the VP shunt tip inside the cyst (Figure 1). Exploratory laparotomy was performed and the tip of the shunt was found inside the cyst, which was opened and drained. The hepatic cyst was found to contain cerebrospinal fluid with no evidence of hydatid disease. The VP shunt was repositioned in his pelvis; our patient made an excellent postoperative recovery and was discharged home after four days. A follow-up CT scan showed regression of the dilated cerebral ventricles (Figure 2a, b).

\section{Discussion}

VP shunts are foreign bodies that may cause intraabdominal complications. Major intra-abdominal complications include ascites, peritoneal infections, intestinal obstructions and perforations, pseudocyst, abscess formation and inguinal hernia. Migration of the distal catheter and metastases of brain tumor have also been reported [1-3]. The incidence of intra-abdominal cerebrospinal fluid (CSF) pseudocyst varies between 1\% and $3 \%$ in different studies. Hepatic pseudocyst secondary to a shunt is extremely rare $[4,5]$.

The formation of an abdominal CSF pseudocyst was first described by Harsh in 1954 [6]. Non-specific clinical presentations may cause diagnostic and therapeutic difficulties; physicians should be aware of this
C Biomed Central

(c) 2011 Faraj et al; licensee BioMed Central Ltd. This is an Open Access article distributed under the terms of the Creative Commons Attribution License (http://creativecommons.org/licenses/by/2.0), which permits unrestricted use, distribution, and reproduction in any medium, provided the original work is properly cited. 


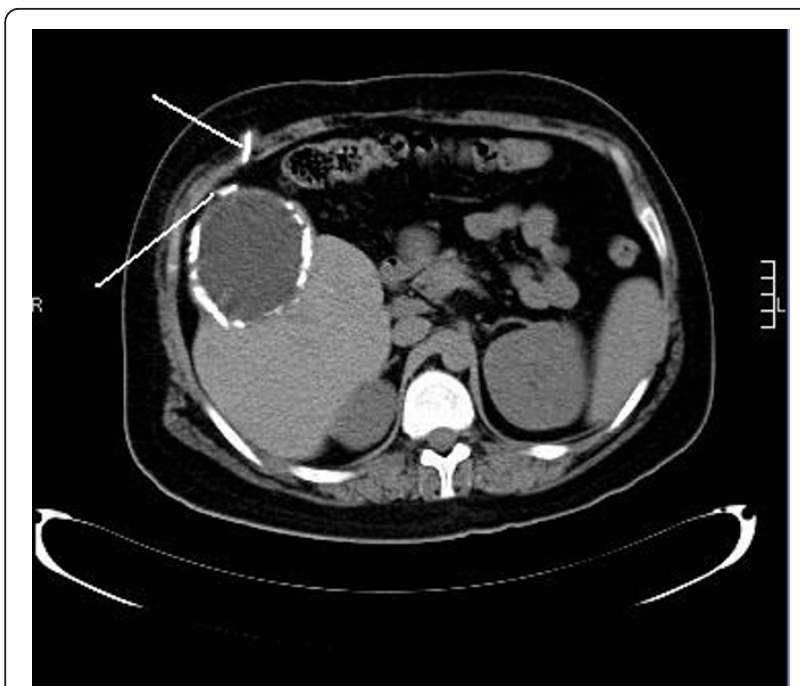

Figure 1 Abdominal CT scan showing $11 \times 9 \mathrm{~cm}$ pseudocyst of his right hepatic lobe, with peripheral calcifications and the tip of the VP shunt going inside the cyst (arrow).

complication, especially in unconscious patients [7]. The precise etiology for abdominal pseudocyst formation is still unknown. An inflammatory process, either sterile or infectious, is generally regarded as the main causative factor [8-10]. Other predisposing factors have been postulated such as peritonitis, prior surgical peritoneal adhesion, a history of central nervous system (CNS) infections and CNS tumors, distal shunt migration, multiple shunt revisions, malabsorption of CSF and allergic reaction $[10,11]$.

The time between last VP shunt operation and development of an abdominal pseudocyst has been reported from three weeks to 10 years [12].

Hepatic pseudocysts secondary to VP shunts are classified as intra-axially or extra-axially growing pseudocysts when penetrating the Glisson capsule; the shunt tube can cause extra-axial subcapsular pseudocyst formation [13]. Alternatively, the tip of the shunt can be lodged in the liver parenchyma and cause formation of an intra-axially growing pseudocyst deep within the parenchyma [14]. The most important factors causing hepatic pseudocyst are migration of the peritoneal tip of the shunt to the liver surface and its chronic irritation [7]. Consequently, the oncotic pressure of the cystic fluid increases, interstitial fluid passes into the cyst, and the cyst increases in size [2].

Hydatid disease is endemic in the Middle East. The combination of imaging and serology are usually used to make the diagnosis. In this case, the initial diagnosis was misled by the radiological findings of peripheral calcifications that may represent the common appearance of hydatid cyst.

Imaging findings of echinococcosis reflect a spectrum depending on the developing stages of the parasitic cyst

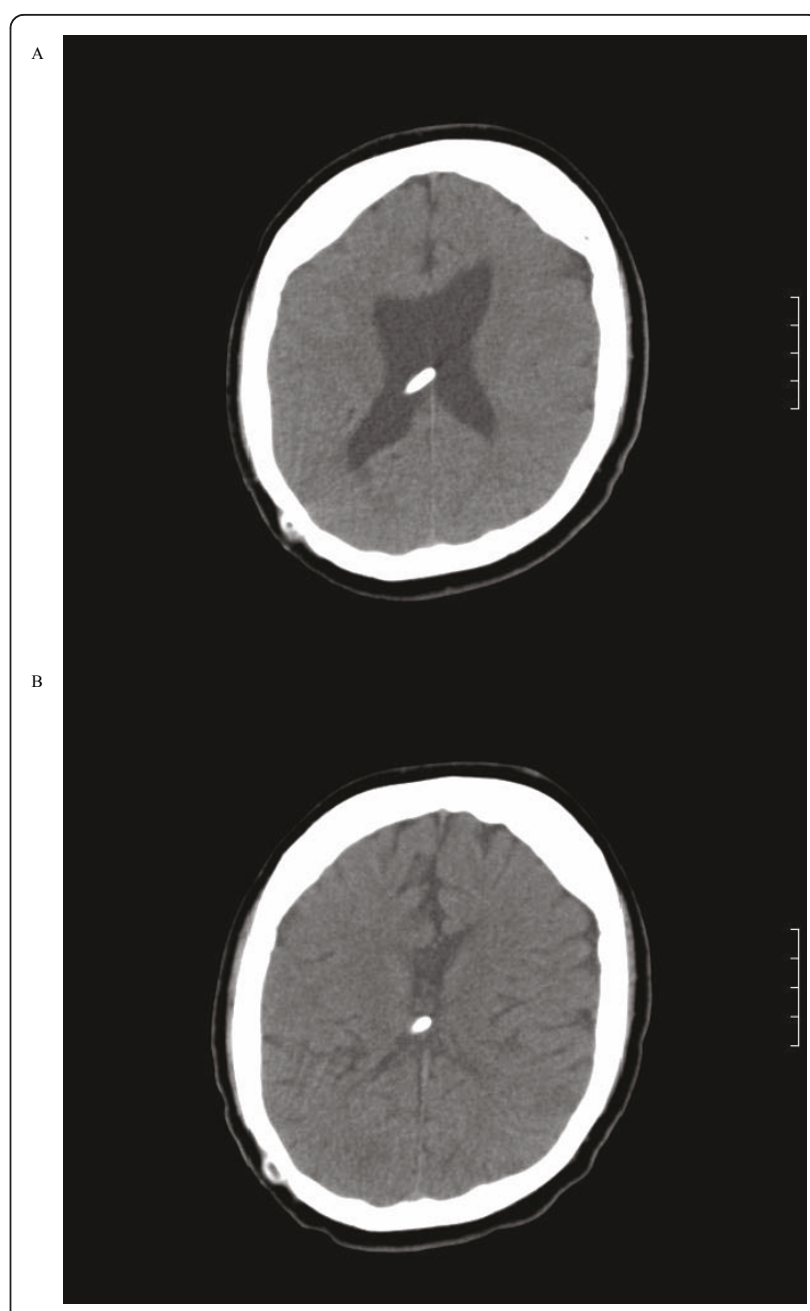

Figure 2 CT scan of the patient's brain. (A) Preoperative ventricular dilatation. (B) Postoperative decompression of the ventricle

in the human tissue, ranging from a single unilocular cyst, to multiple daughter cyst formation, and then gradually to a solid and calcified cyst [15].

The fact that the hydatid indirect hemagglutinin (IHA) test was negative does not rule out hydatid disease however, in retrospect, would make a peritoneal cyst or pseudocyst as likely. The sensitivity and specificity of the IHA are $86.7 \%$ and $95 \%$ respectively [16]. Only a positive hydatid serology is valuable; a negative serologic test does not exclude the diagnosis [17].

The suspicion of an abdominal pseudocyst is often made at the time of physical examination and on the basis of conventional radiology [7]. Visualization of the distal tip of the VP shunt within a homogeneous intraperitoneal collection is the principal diagnostic sign of an abdominal CSF pseudocyst on ultrasound and CT. Ultrasonography is the method of choice because it is fast and reliable [8]. However, a CT scan of the 
abdomen provides a more accurate diagnosis [18]. For the diagnosis of an extra-axially growing hepatic pseudocyst, abdominal CT images are typical. The pseudocyst is surrounded by an annulus showing continuity with hepatic tissue [13].

The standard treatment of a hepatic pseudocyst secondary to catheter tip migration, in cases with no infection or prominent inflammatory reaction in the peritoneal cavity, should be simple repositioning of the peritoneal catheter in the abdominal cavity. This procedure may be combined with percutaneous or open drainage in resistant cases [3]. However, there are numerous therapeutic approaches for the management of shuntrelated abdominal pseudocysts reported in the literature [19]; simple aspiration of the cyst under CT or ultrasound guidance [5]; removal of the shunt and installation of a new one once the cyst is resolved; if it is not resolved, shunt revision following cyst aspiration; or draining the cyst fluid through a explorative laparotomy, unroofing the cyst wall, then shunt revision or repositioning. In recent years, laparoscopic approaches have been advocated [20].

\section{Conclusion}

We report a case of a hepatic CSF pseudocyst secondary to the migration of a VP shunt, mistaken for hepatic hydatid disease with serious sequelae. The formation of a pseudocyst should always be considered in patients with VP shunts in situ and can be easily treated by simple repositioning.

\section{Consent}

Written informed consent was obtained from the patient for publication of this manuscript and any accompanying images. A copy of the written consent is available for review by the Editor-in-Chief of this journal.

\section{Abbreviations \\ CNS: central nervous system; CSF: cerebrospinal fluid; CT: computed tomography; IHA: indirect hemagglutinin; VP: ventriculo-peritoneal.}

\section{Authors' contributions}

WF drafted the manuscript; HHA and DM participated in the design of the study; MK participated in the design and coordination of the study. Al authors read and approved the final manuscript.

\section{Competing interests}

The authors declare that they have no competing interests.

Received: 7 February 2011 Accepted: 23 September 2011 Published: 23 September 2011

\section{References}

1. Jain $S$, Bhandarkar D, Shah R, Vengsarkar U: Laparoscopic management of complicated ventriculoperitoneal shunts. Case report. Neurol India 2003, 51:269-270.

2. Ersahin Y, Mutluer S, Tekeli G: Abdominal cerebrospinal fluid pseudocysts. Childs Nerv Syst 1996, 12:755-758.
3. Kaplan M, Ozel SK, Akgun B, Kazez A, Kaplan S: Hepatic pseudocyst as a result of ventriculoperitoneal shunts: case report and review of the literature. Pediatr Neurosurg 2007, 43:501-503.

4. Pathi $R$, Sage M, Slavotinek J, Hanieh A: Abdominal cerebrospinal fluid pseudocyst. Case report. Australas Radiol 2004, 48:61-63.

5. Roitberg BZ, Tomita T, McLone DG: Abdominal cerebrospinal fluid pseudocyst: a complication of ventriculoperitoneal shunt in children. Pediatr Neurosurg 1998, 29:267-273.

6. Harsh GR: Peritoneal shunt for hydrocephalus: utilizing the fimbria of the fallopian tube for entrance to the peritoneal cavity. J Neurosurg 1954, 11:284-294.

7. Hsieh $C T$, Pai CC, Tsai TH, Chiang YH, Su YH: Hepatic cerebrospinal fluid pseudocyst: a case report and review of the literature. Neurol India 2006, 54:86-88.

8. Mobley LW, Doran SE, Hellbusch LC: Abdominal pseudocyst: predisposing factors and treatment algorithm. Pediatr Neurosurg 2005, 41:77-83.

9. Salomao JF, Leibinger RD: Abdominal pseudocysts complicating CSF shunting in infants and children. Report of 18 cases. Pediatr Neurosurg 1999, 31:274-278.

10. Rainov N, Schobess A, Heidecke V, Burkert W: Abdominal CSF pseudocysts I patients with ventriculo-peritoneal shunts. Report of fourteen cases and review of the literature. Acta Neurochir (Wien) 1994, 127:73-78.

11. Hashimoto M, Yokota A, Urasaki E, Tsujigami S, Shimono M: A case of abdominal CSF pseudocyst associated with silicone allergy. Childs Nerv Syst 2004, 20:761-764.

12. Pernas JC, Catala J: Case 72: Pseudocyst around ventriculoperitoneal shunt. Radiology 2004, 232:239-243.

13. Wang F, Miller $\mathrm{JH}$ : Cerebrospinal fluid pseudocyst presenting as a hepatic mass: a complication of ventriculoperitoneal shunt. Short reports. Pediatr Radiol 1989, 19:326-327.

14. Naveen C, Rahul G, Singla SL, Sharma NK: Lower end of ventriculoperitoneal shunt embedding in liver parenchyma. Letter to the editor. Neurol India 2004, 52:405.

15. Eckert J, Deplazes P: Biological, epidemiological, and clinical aspects of echinococcosis, a zoonosis of increasing concern. Clin Microbiol Rev 2004, 17:107-135.

16. El-Shazly AM, Saad RM, Belal US, Sakr T, Zakae HA: Evaluation of ELISA and IHAT in serological diagnosis of proven cases of human hydatidosis. J Egypt Soc Parasitol 2010, 40:531-538.

17. Leow CK, Lau WY: Soft-tissue images. Hydatid disease of the liver. Can J Surg 2000, 43:330-331.

18. Coley BD, Shiels WE, Elton S, Murakami JW, Hogan MJ: Sonographically guided aspiration of cerebrospinal fluid pseudocysts in children and adolescents. AJR Am J Roentgenol 2004, 183:1507-1510.

19. Ersahin Y, Mutluer S, Tekeli G: Abdominal cerebrospinal fluid pseudocysts. Childs Nerv Syst 1996, 12:755-775.

20. Rana SR, Quivers ES, Haddy TB: Hepatic cyst associated with ventriculoperitoneal shunt in a child with brain tumor. Childs Nerv Syst 1985, 1:349-351.

doi:10.1186/1752-1947-5-475

Cite this article as: Faraj et al:: Hepatic cerebrospinal fluid pseudocyst mimicking hydatid liver disease: a case report. Journal of Medical Case Reports 2011 5:475

\section{Submit your next manuscript to BioMed Central and take full advantage of:}

- Convenient online submission

- Thorough peer review

- No space constraints or color figure charges

- Immediate publication on acceptance

- Inclusion in PubMed, CAS, Scopus and Google Scholar

- Research which is freely available for redistribution 